\title{
Evaluation of Development Strategies for Kaohsiung Port Using a Goals Achievement Method
}

\section{Wen-Chih Huang}

Associate Professor, Department of Harbor and River Engineering, National Taiwan Ocean University, Keelung, Taiwan 202., huangwc@mail.ntou.edu.tw

Follow this and additional works at: https://jmstt.ntou.edu.tw/journal

Part of the Civil and Environmental Engineering Commons

\section{Recommended Citation}

Huang, Wen-Chih (2004) "Evaluation of Development Strategies for Kaohsiung Port Using a Goals Achievement Method," Journal of Marine Science and Technology. Vol. 12: Iss. 4, Article 13.

DOI: 10.51400/2709-6998.2254

Available at: https://jmstt.ntou.edu.tw/journal/vol12/iss4/13

This Research Article is brought to you for free and open access by Journal of Marine Science and Technology. It has been accepted for inclusion in Journal of Marine Science and Technology by an authorized editor of Journal of Marine Science and Technology. 


\section{Evaluation of Development Strategies for Kaohsiung Port Using a Goals Achievement Method}

\section{Acknowledgements}

The authors would like to thank National Science Council of the Republic of China for its support of the research NSC 89-2611-E-019-032. The content of this paper is part of the results from that study. 


\title{
EVALUATION OF DEVELOPMENT STRATEGIES FOR KAOHSIUNG PORT USING A GOALS ACHIEVEMENT METHOD
}

\author{
Wen-Chih Huang*
}

Keywords: strategic evaluation, port development, goals achievement, Kaohsiung Port.

\section{ABSTRACT}

The Port of Kaohsiung was the third largest container port in the world before 1999, although it dragged to sixth place by 2003. In order to increase the port's competitiveness, this research outlines six goals and twenty-seven strategies from the viewpoint of international logistics. This research uses the goals achievement measurement for strategic planning effectiveness, and it was undertaken to develop the Goals Achievement Evaluation Model (GAEM) to cope with the problems of a large number of strategies and ambiguity in strategic definition. The GAEM uses a two-stage Delphi questionnaire by simplifying the quantity of responses on the survey. The weights of the goals were measured, and elements of the goal-strategy (GS) matrix were selected for the first-stage survey. The interviewees scored the elements for the second-stage survey. Through the GAEM framework, the number of strategic performances has been reduced to one-fourth of the original GS elements for this case. The most preferred strategies would be to promote the redevelopment of the old wharves through urban planning, together with five other items.

\section{INTRODUCTION}

Due to the rapid growth of international trade, in recent years the container shipping volume of the major container ports in East Asia has accounted for $50 \%$ of the global total [13]. As a consequence the countries of this region have invested vigorously in berth construction, leading to intensive competition among those ports. In East Asian, competition among the main container ports of Japan, China, Hong Kong, Korea, Singapore, and Taiwan is a type of regional competition as classified by Verhoeff [18].

The annual quantities of containers being loaded and unloaded in Hong Kong and Singapore have steadily been in the first and second places for the past few years. In can trast, the rankings for the ports of Kaohsiung,

Paper Submitted 07/12/04, Accepted 10/14/04. Author for Correspondence: Wen-Chih Huang. E-mail: huangwc@mail.ntou.edu.tw.

*Associate Professor, Department of Harbor and River Engineering, National Taiwan Ocean University, Keelung, Taiwan 202.
Pusan and Shanghai, for quantities of loading and unloading containers has been rather varied. In 2002, the port of Kaohsiung's annual container volume dropped to fifth place, white Shanghai, which was ranked below $20^{\text {th }}$ a decade ago, had advanced to fourth place. Then Kaohsiung's annual container volume retreated to sixth place behind Shenzheng, which was in the fifth place in the year 2003 [2]. In regard to transshipment, Kaohsiung, Hong Kong and Shanghai, which are, geographically situated in a triangular relationship, are in direct and heated competition with each other. The annual transshipment volumes for Kaohsiung and Hong Kong are about 2.5 and 3.0 million TEUs respectively; and only about 0.15 million TEUs for Shanghai [10], which depends upon china's vast inland regions to back up imports and exports as the principle item, with transshipment as a minor facet. Hong Kong and Kaohsiung can attract southern China's cargo, as long as the relative benefit and effectiveness for carriers is better than in Shanghai.

In order to increase the competitiveness of the region, the port of Kaohsiung is enhancing its loading and unloading efficiency, its quality of information, and the process/re-export industry of this area. Moreover, the highest priority is to propose its development strategies. The port should extend its viewpoint of the structure for the integration of ports and the surrounding city by considering the internal and external effectiveness of the port as a whole. The issues that have to be considered are relative factors, such as port redevelopment and urban planning, comprehensive land-use planning, financial issues, sustainable development, transportation, industry and global logistics management, and the re-engineering the organization of port management. In other words, the development of the port should combine the original transport, production value-added stages into one with service value-added of global logistics management [15]. Given the present conditions, guiding Kaohsiung's development strategies should be a first priority. Thus, this study formulates development strategies and selects more effective ones for the port of Kaohsiung. 
Previously cost benefit analysis (CBA), a single criterion method, was considered a major strategic evaluation approach [4]. However, it was criticized for being a black box process, until Hill $[8,9]$ put forward the goals achievement matrix (GAM) to cope with the lack of clarity. The GAM, a perfect structure, can bring analyzed influence from wide areas and activities compared to the traditional CBA. The GAM also can handle qualitative and quantitative data at the same time. Later, David [3] combined SWOT, to determine evaluation indicators and established a quantitative strategic planning matrix (QSPM) for strategic evaluation. The QSPM is often used for selecting business strategies with few strategic quantities. However, in the case of a public sector with a large number of strategies, this model needs a large amount of data. The multicriteria decision-making (MCDM) approaches, such as analytic hierarchy process (AHP) can be used for strategic evaluation [4]. On the same layer of the AHP, the number of factors compared does not exceed seven. Foster and Foster [6] and Dyson and Foster [5] presented goals achievement and multi-dimensional as measurement views of strategic planning effectiveness. This study classifies evaluation approaches into the three categories of MCDM, single criterion, and goals achievement (GA) (see Figure 1). MCDM methods adopted to assess

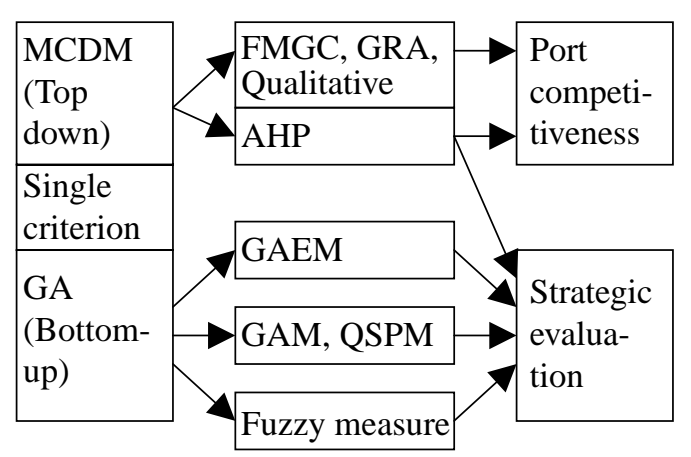

Fig. 1. Categories of evaluation methods.

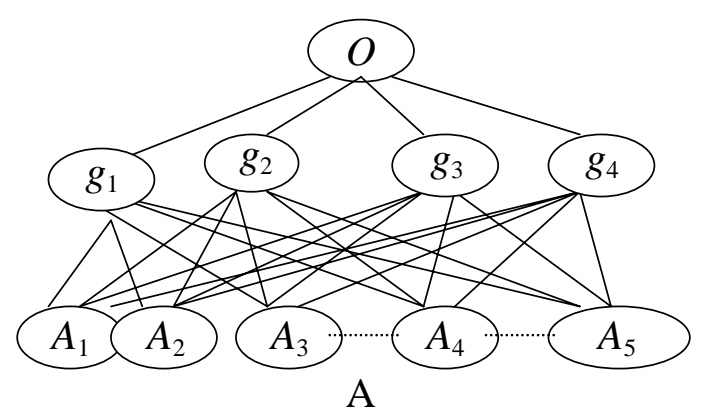

port competitiveness include AHP [10, 12], GRA [11], and Fuzzy multicriteria grade classification [13]. GAM and QSPM are goals achievement approaches. Since a perfect evaluation structure, such as GAM and QSPM, requires much information, this study develops a strategic evaluation model of an imperfect structure to reduce the evaluation data required and to handle the evaluation of the port developmental strategies.

Strategic decision-making is designed to solve inconsistencies between various divisions using effective strategies [7]. The research on strategic evaluation focuses on evaluating strategies for the port and the city of Kaohsiung as developmental guidelines and building Goals Achievement Evaluation Model (GAEM) in the analysis to cope with the problems of a large amount of strategies and ambiguity in strategic definition. Throughout the model, the number of strategic performances has been reduced of the original goal strategy elements. This model would provide a pertinent evaluation tool for the port strategic analysis.

The rest of this paper is organized as follows: Part two constructs the methodology of the algorithm for the GAEM. Part three is an empirical study for the case of Kaohsiung. The discussion on the model follows in Part four, and finally in Part five concluding remarks for this study are made. In the following section, the GAEM model is presented.

\section{METHODOLOGY}

This research applies a degree of measurement where strategies achieve goals from bottom-up ideas by establishing an imperfect evaluation structure. Namely, the strategy is linked to some of the goals on the upper level [Figure 2(A)], but not all the goals [Figure 2(B)], to reduce the survey data. For example, strategy $s_{1}$ is only linked to $g_{1}$ and $g_{2}$, not to $g_{3}$ and $g_{4}$. Development strategies for Kaohsiung are of both public sector nature and a macro attribute. In the planning stage, the strategy is to develop a guidance system and to contain any

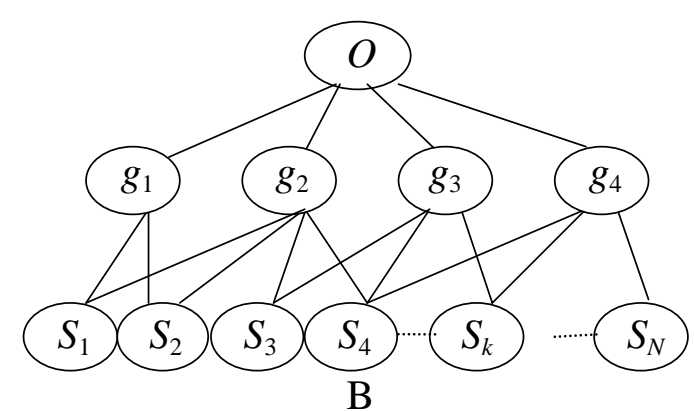

Fig. 2. Perfect (A) and imperfect (B) hierarchical evaluation structure. 
ambiguous concepts. Since is difficult to precisely measure strategic performance, this research adopts the evaluation hierarchy, including overall objective, goal, and alternatives [1], and weighted scoring technique of the multiple goals method to establish the effect matrix for goals and strategies called GAEM in the following analysis.

The major parts of the evaluation model include the following two [14, 17, 19]:

1. Effect appraisal: Use the logics method to outline the alternatives and measure their possible effects under specific attributes. Then, establish the effect matrix of the alternatives.

2. Policy analysis: Proceed to a trade-off analysis of the alternatives and attributes according to the results of the effect appraisal. Methods include monetary evaluation, weighted summation, interacting method, etc.

This section applies a two-stage Delphi questionnaire to filter out the elements of the goal strategy (GS) matrix, to survey goals' weights and to obtain consensus performances for strategies linked to relevant goals. The GAEM hierarchy includes three layers, the overall objective, goals, and alternatives. The algorithm of the GAEM is described as follows:

\section{Step 1. Construct an initial GS matrix.}

Given $m$ number of goals $G=\left(g_{1}, \ldots, g_{i}, \ldots, g_{m}\right)(m$ $\geq 2)$, n number of strategies $S=\left(s_{1}, \ldots, s_{j}, \ldots, s_{n}\right)(n \geq 2)$. The elements of relation among goals and strategies are shown in the GS matrix $\boldsymbol{A}=\left[a_{i j}\right]$ shown as Table 1.

\section{Step 2. Undertake the first Delphi questionnaire survey.}

The questionnaire survey in this stage includes two sorts of data in the GS matrix, i.e., $m$ number of goal's weights $\boldsymbol{W}=\left[w_{1}, \ldots, w_{i}, \ldots, w_{m}\right](m \geq 2)$, and the relationship between the goal and strategy judged by $q$ number of interviewees. The interviewees need to decide if the strategy $j$ can or cannot reach goal $i$.

If the interviewee $f$ thinks that $j$ strategy can achieve

Table 1. Goal-strategy (GS) matrix

\begin{tabular}{|c|c|c|c|c|c|}
\hline \multirow[b]{2}{*}{ Strategies } & \multicolumn{5}{|c|}{ Goals } \\
\hline & $\begin{array}{c}g_{1} \\
\left(w_{1}\right)\end{array}$ & ... & $\begin{array}{c}g_{i} \\
\left(w_{i}\right)\end{array}$ & ... & $\begin{array}{c}g_{m} \\
\left(w_{m}\right)\end{array}$ \\
\hline$s_{1}$ & & & \multirow{5}{*}[a_{ij}]{} & & \\
\hline$\vdots$ & & & & & \\
\hline$s_{j}$ & & & & & \\
\hline$\vdots$ & & & & & \\
\hline$s_{n}$ & & & & & \\
\hline
\end{tabular}

$i$ goal, then matrix element $a_{i j}^{f}(f=1,2, \ldots, q)$ gets one point. The formula is illustrated as (1) and (2).

$$
\begin{aligned}
& a_{i j}^{f}=\left\{\begin{array}{l}
1, \text { strategy } j \text { reaches goal } i \\
\text { judged by interviewee } f . \\
0, \text { others }
\end{array}\right. \\
& a_{i j}^{f}=\sum_{f=1}^{q} a_{i j}^{f}, \forall i, j
\end{aligned}
$$

Weight of goal $g_{i}$ by interviewee $f$ is $w_{i f}$.

$$
w_{i f}=\frac{S_{i f}^{w}}{T S_{f}^{w}}, \forall i, j
$$

where:

$S_{i f}^{w}$ : Goal's weighting score for strategy $i$ by $f$ interviewee; scale is $1 \sim 10$.

$T S_{f}^{w}$ : Total score of relative importance for $m$ number of goals by interviewee $f$.

$$
T S_{f}^{w}=\sum_{i=1}^{m} S_{i f}^{w}, \forall f
$$

According to $q$ number of interviewees' normalized results $w_{i f}$, the weight of each goal $g_{i}$ is shown as $\boldsymbol{W}$ $=\left[w_{i}\right]$.

$$
w_{i}=\frac{1}{q} \sum_{f=1}^{q} w_{i f}, \forall i, f
$$

The weight of goal $w_{i}$ satisfies the following conditions.

$$
\begin{aligned}
& 0 \leq w_{i} \leq 1, \forall i \\
& \sum_{i=1}^{n} w_{i}=1
\end{aligned}
$$

\section{Step 3. Choose the GS relationship.}

Relational links between goal and strategy are filtered out based on the element scores of the GS matrix $\boldsymbol{A}$ from the first survey. The interviewees decided the threshold $T$, such as $75 \%$, on a major rule basis. The element of matrix $a_{i j}$ reserved from the previous step is $b_{i j}$, which is shown as formula (8).

$$
b_{i j}=\left\{\begin{array}{l}
1, \text { If } a_{i j} \geq T, \\
0, \text { others }
\end{array} \forall i, j\right.
$$

Moreover, some rules are proposed to deal with the condition that a goal might not link to a strategy and therefore would be useless. This case is in conflict with the previous step that all goals gain their weights. To prevent goals that have no strategy linked to them from obtaining high weights, this study suggests the following operational rules. 
1. Each goal maps to at least one strategy. Therefore, if a goal is linked to no strategy, then the following options are applied. First, if there are more than seven goals, then, the goal(s) with no strategy to link with can be deleted. Second, if there are fewer than seven goals, the strategy obtaining the greatest performance score under that goal is reserved, even if it does not pass the threshold. Third, undertake another survey to review the strategies under the threshold.

2. If a certain strategy does not pass the threshold for all goals, then this strategy can be deleted.

\section{Step 4. Establish the GS relations with consensus.}

According to the operational rules described above, we may adjust the GS relations and finally obtain the matrix $\boldsymbol{B}$. The structure of this GAEM model is as shown in Figure 2.

$$
\boldsymbol{B}=\left[b_{i j}\right]
$$

\section{Step 5. Embark on a second questionnaire survey.}

Strategy $j$ maps to goal $i$, and the GS relational matrix under an imperfect structure is shown as $\boldsymbol{B}$. Performance values are scored as $c_{i j}^{f}$ by interviewee $f$ according to elements of matrix $\boldsymbol{B}$. The scoring scale for performance is also from 1 to 10 . It is better for planners to provide a clear scoring rule to avoid inconsistency. According to $q$ interviewees' scoring results $c_{i j}^{f}$, we obtain element $C_{i j}$ of $\boldsymbol{C}$ by use of arithmetic average performance.

$$
C_{i j}=\sum_{f=1}^{q} c_{i j}^{f} / q, \quad \forall i, j
$$

\section{Step 6. Calculate the synthesized performance values of the strategies.}

The final synthesized performance of the strategy is $\boldsymbol{D}=\left[d_{j}\right]$, multiplication of arithmetic average performance and goal weight (Table 2). Shown as formula

\begin{tabular}{|c|c|c|c|c|c|c|}
\hline \multirow[b]{2}{*}{$\begin{array}{c}\text { Strategies } \\
s_{j}\end{array}$} & \multicolumn{5}{|c|}{ Goals } & \multirow[b]{2}{*}{ D } \\
\hline & $\begin{array}{c}g_{1} \\
\left(w_{1}\right)\end{array}$ & $\ldots$ & $\begin{array}{c}g_{i} \\
\left(w_{i}\right)\end{array}$ & $\ldots$ & $\begin{array}{c}g_{m} \\
\left(w_{m}\right)\end{array}$ & \\
\hline $\begin{array}{c}s_{1} \\
\vdots\end{array}$ & $\begin{array}{c}c_{11} \\
\vdots\end{array}$ & $\begin{array}{c}0 * \\
\vdots\end{array}$ & $\ldots$ & $\begin{array}{l}0 \\
\vdots\end{array}$ & $\begin{array}{c}d_{1} \\
\vdots\end{array}$ & \\
\hline $\begin{array}{c}s_{j} \\
\vdots\end{array}$ & $\begin{array}{c}\dot{c}_{1 j} \\
\vdots\end{array}$ & $\begin{array}{c}\dot{c}_{i j} \\
\vdots\end{array}$ & $\ldots$ & $\begin{array}{c}c_{m j} \\
\vdots\end{array}$ & $\begin{array}{c}\dot{d}_{j} \\
\vdots\end{array}$ & \\
\hline sn & $\dot{0}$ & $\dot{0}$ & $\ldots$ & $\mathrm{cmm}$ & $\dot{d}_{n}$ & \\
\hline
\end{tabular}

Table 2. Strategic performance matrix

*: Elements are deleted.
(11).

$$
D=C \cdot W^{T}
$$

\section{Step 7. Rank evaluation strategies.}

Rank the order of the alternatives depending on the synthesized performance values $\boldsymbol{D}$ of the strategies. The larger the synthesized performance is, the better the strategy achieves the overall objective.

\section{EMPIRICAL STUDY}

The port of Kaohsiung contains 25 container berths, is $7455 \mathrm{~m}$ in length, and $-10.5 \mathrm{~m}$ to $-15.0 \mathrm{~m}$ in depth, has a container station with an area of 277.6 hectares, and 64 sets of container cranes. It dropped to the ranking of sixth container port in the world in 2003. Its projects include primarily three stages: The $1^{\text {st }}$ stage projects are to complete the fifth container terminal, and increase the container handling capacity to 3,000,000 TEUs. The $2^{\text {nd }}$ stage plans (from 2001 to 2004) are to finish the construction of berths \#58, \#65, \#66, and to convert berths \#S1, \#18 to \#21 and the ships factory into a waterfront district. The $3^{\text {rd }}$ stage projects (2005 and later) are to develop the outer waters as a bulk distribution center for southern Taiwan, allowing it to deal with 7,000 TEUs and future 15,000 TEU containerships, to build a second overpass or underground tunnel across the port, in order to carry out a redevelopment of the old wharves, and to complete an outbound highway link to the port areas.

The port of Kaohsiung should focus on correcting its weaknesses and at the same time preserve its current competitive advantages when drafting development strategies for resource integration. The following paragraph proposes goals and development strategies for the port of Kaohsiung. GAEM is used in the analysis to cope with the problems of a large number of strategies and of ambiguity in strategic definition.

In order to ensure that Kaohsiung is fully effective and competitive, this study sets a vision and goals for the integration of its resources. This section sets Kaohsiung's goal as being the maritime and cultural capital city of the new world of the Southern Taiwan. The overall objective is to establish a highly competitive port and city with sustainable development, having a high and sustainable quality of life. This paper considers the organizational, urban and port's land-use, transportation, logistics, as well as the sustainability aspects of the port, and sets up six developmental goals as follows:

$g_{1}$ : Achieving integration of all relevant resources of the port's organization. 
$g_{2}$ : Achieving the effective and efficient usage of the port's land between the port and the city.

$g_{3}$ : High quality of the software and hardware for the old wharves.

$g_{4}$ : High quality inland transportation connecting the port and the interior of Taiwan.

$g_{5}$ : Achieving a global logistics management system.

$g_{6}$ : Achieving a modern metropolis with a sustainable operation, and an economy based on knowledge and technology.

In order to formulate the developmental strategies, seven issues are induced from the current condition of Kaohsiung, including 1) port redevelopment and urban renewal, 2) the multi-functional international trade and logistics park, 3) integrated land-use planning, 4) issues of transportation, 5) diversification and financial perspective, 6) knowledge-based economy and sustainable development, and 7) integration in organization. Under the overall objective, this research adopts twentyseven strategies [16] (shown as APPENDIX) as the developmental guidelines of the port according to these seven issues.

By surveying experts and professionals, we received twelve copies of valid questionnaires. The results from the GAEM operation are shown in Table 3. In the first stage Delphi questionnaire survey, goals in response to strategies are as follows: Goal $g_{1}$ is linked to strategies $s_{1}, s_{2}, s_{15}$, and $s_{21}$. Goal $g_{2}$ is linked to strategies $s_{1}, s_{3}, s_{4}, s_{5}, s_{6}, s_{7}, s_{12}, s_{13}, s_{14}$, and $s_{17}$. Goal $g_{3}$ is linked to strategies $s_{6}, s_{7}, s_{13}, s_{14}, s_{25}$, and $s_{26}$. Goal $g_{4}$ is linked to strategies $s_{8}, s_{9}, s_{10}$, and $s_{18}$. Goal $g_{5}$ is linked to strategies $s_{9}, s_{11}, s_{12}, s_{13}, s_{16}, s_{18}, s_{19}, s_{21}, s_{22}, s_{23}, s_{24}$, and $s_{26}$. Goal $g_{6}$ is linked to strategies $s_{20}, s_{22}$, and $s_{27}$. The weights of the goals investigated by the survey are computed by statistics of the results according to formula (5). The weight of goal $g_{1}$, re-engineering of the organizational system of the municipality and the port, is $20.16 \%$. The weight of $g_{2}$, effective use of municipal and port land, is $17.66 \%$. The weight of $g_{3}$, enhancing the software and hardware of the old wharves,

Table 3. Second stage performance values

\begin{tabular}{|c|c|c|c|c|c|c|c|}
\hline $\begin{array}{c}\text { Strategies } \\
\left(s_{j}\right)\end{array}$ & $\begin{array}{c}g_{1} \\
(20.16 \%) \\
\end{array}$ & $\begin{array}{c}g_{2} \\
(17.66 \%) \\
\end{array}$ & $\begin{array}{c}g_{3} \\
(10.35 \%) \\
\end{array}$ & $\begin{array}{c}g_{4} \\
(16.34 \%) \\
\end{array}$ & $\begin{array}{c}g_{5} \\
(20.25 \%) \\
\end{array}$ & $\begin{array}{c}g_{6} \\
(15.24 \%) \\
\end{array}$ & D \\
\hline$s_{1}$ & 8.97 & 6.92 & - & - & - & - & 3.030 \\
\hline$s_{2}$ & 4.79 & - & - & - & - & - & 0.967 \\
\hline$s_{3}$ & - & 7.59 & - & - & - & - & 1.340 \\
\hline$s_{4}$ & - & 7.03 & - & - & - & - & 1.241 \\
\hline$s_{5}$ & - & 8.53 & - & - & - & - & 1.506 \\
\hline$s_{6}$ & - & 7.16 & 7.59 & - & - & - & 2.050 \\
\hline$s_{7}$ & - & 6.41 & 6.66 & - & - & - & 1.917 \\
\hline$s_{8}$ & - & - & - & 7.99 & - & - & 1.995 \\
\hline$s_{9}$ & - & - & - & 7.52 & 8.24 & - & 2.898 \\
\hline$s_{10}$ & - & - & - & 8.06 & - & - & 1.317 \\
\hline$s_{11}$ & - & - & - & - & 7.81 & - & 1.581 \\
\hline$s_{12}$ & - & 6.55 & - & - & 6.16 & - & 2.405 \\
\hline$s_{13}$ & - & 6.76 & 8.36 & -0 & 8.40 & - & 3.761 \\
\hline$s_{14}$ & - & 7.46 & 6.76 & - & - & - & 2.183 \\
\hline$s_{15}$ & 4.14 & - & - & - & - & - & 1.535 \\
\hline$s_{16}$ & - & - & - & - & 8.11 & - & 1.642 \\
\hline$s_{17}$ & - & 5.32 & - & - & - & - & 0.940 \\
\hline$s_{18}$ & - & - & - & 6.66 & 6.83 & - & 2.470 \\
\hline$s_{19}$ & - & - & - & - & 7.32 & - & 1.483 \\
\hline$s_{20}$ & - & - & - & - & - & 6.70 & 1.021 \\
\hline$s_{21}$ & 5.67 & - & - & - & 6.91 & - & 2.543 \\
\hline$s_{22}$ & - & - & - & - & 7.06 & 8.04 & 2.656 \\
\hline$s_{23}$ & - & - & - & - & 6.85 & - & 1.387 \\
\hline$s_{24}$ & - & - & - & - & 5.57 & - & 1.128 \\
\hline$s_{25}$ & - & - & 7.79 & - & - & - & 0.806 \\
\hline$s_{26}$ & - & - & 6.28 & - & 6.06 & - & 1.878 \\
\hline$s_{27}$ & - & - & - & - & - & 5.64 & 0.860 \\
\hline
\end{tabular}

Note: performance values are scored from 1-10. 
is $10.35 \%$. The weight of $g_{4}$, enhancing transportation in the municipality and the port, is $16.34 \%$. The weight of $g_{5}$, enhancing the competitiveness of Kaohsiung, is $20.25 \%$, making it the highest goal. The weight of $g_{6}$, creating a modern metropolis with sustainable development and a knowledge-based economy, is $15.24 \%$. Therefore, the strengthening of the competitiveness is an important goal. Through the second stage Delphi questionnaire survey, the results of goals and the performance values of strategies $\left(c_{i j}\right)$ are illustrated as Table 3 . The synthesized performance matrix $\boldsymbol{D}$ is calculated by formula (11) in section 2. Strategies are ranked according to values of $\boldsymbol{D}$ (Table 4.).

Synthesized performance scores represent the relative achievement of a strategy to reach the development objective. The research sorts the superior strategies by accumulation of performance values. The summation of performance scores for the top nine strategies exceeds half of the total. Those strategies have a concensus for the interviewees. The superior strategies include the following nine. Strategy $s_{13}$ : promotion of the redevelopment of the old wharves, while international logistics should be re-defined as an economic investment on a national and international level. Strategy $s_{\mathbf{1}}$ : incorporate the development project and urban plan of the port by reinforcing the existing ODA's function under the structure of an integrated port and city. Strategy $\boldsymbol{s}_{\mathbf{9}}$ : speed up and strengthen the traffic link between the Process Export Zone and the container terminals. Strategy $\boldsymbol{s}_{22}$ : integrate the current maritime network, MTNet, Port-Net, and Trade-VAN into a navigation, port, tariff information system. Strategy $\boldsymbol{s}_{\mathbf{2}}$ : the city government invests internationally combining Port Bureau,

Table 4. Performances and orders for strategies

\begin{tabular}{cccccc}
\hline$s_{j}$ & Values/orders & & $s_{j}$ & Values/orders \\
\hline$s_{1}$ & 3.030 & $(2)$ & $s_{15}$ & 1.535 & $(15)$ \\
$s_{2}$ & 0.967 & $(24)$ & $s_{16}$ & 1.642 & $(13)$ \\
$s_{3}$ & 1.340 & $(19)$ & $s_{17}$ & 0.940 & $(25)$ \\
$s_{4}$ & 1.241 & $(21)$ & $s_{18}$ & 2.470 & $(6)$ \\
$s_{5}$ & 1.506 & $(16)$ & $s_{19}$ & 1.483 & $(17)$ \\
$s_{6}$ & 2.050 & $(9)$ & $s_{20}$ & 1.021 & $(23)$ \\
$s_{7}$ & 1.917 & $(11)$ & $s_{21}$ & 2.543 & $(5)$ \\
$s_{8}$ & 1.995 & $(10)$ & $s_{22}$ & 2.656 & $(4)$ \\
$s_{9}$ & 2.898 & $(3)$ & $s_{23}$ & 1.387 & $(18)$ \\
$s_{10}$ & 1.317 & $(20)$ & $s_{24}$ & 1.128 & $(22)$ \\
$s_{11}$ & 1.581 & $(14)$ & $s_{25}$ & 0.806 & $(27)$ \\
$s_{12}$ & 2.405 & $(7)$ & $s_{26}$ & 1.878 & $(12)$ \\
$s_{13}$ & 3.761 & $(1)$ & $s_{27}$ & 0.860 & $(26)$ \\
$s_{14}$ & 2.183 & $(8)$ & & & \\
& $\Sigma$ & & & 48.539 & \\
\hline
\end{tabular}

Note: Numerical orders are in parentheses. carriers, major business clients and intelligent service suppliers, as part of their investment portfolio. Strategy $s_{18}$ : adopt Kaohsiung's strength of airport and seaport by enhancing the functions of the sea-air reprocessing and transshipment services. Strategy $\boldsymbol{s}_{\mathbf{1 2}}$ : review the supply and demand situation of the domestic fisheries, and relocate the fishery operations to other exclusive zones or other dedicated fishery ports. Strategy $\boldsymbol{s}_{\mathbf{1 4}}$ : integrate the redevelopment of the old wharves with the urban renewal projects, covering the overall planning, general consultancy, facility planning, master development entity, development and operational consideration. And Strategy $\boldsymbol{s}_{\mathbf{6}}$ : develop the Chizin Peninsula similar to the Santosa project in Singapore with a redevelopment cultural, recreational and leisure facilities, including natural ecology and historical sites. Those are nine superior strategies in order of superiority, having concensus among the interviewees.

\section{DISCUSSION}

This section discusses the logic of choosing a superior strategy quantity. If the top $80 \%$ of the total synthesized performance as 48.539 is adopted, according to the Pareto rule of major $80 \%$, then the number of superior strategies will be up to 18 items. In this case, the number of superior strategies is approximately $67 \%$ of the original strategies, which does not meet the purpose of filtering out. If the top $50 \%$ of the total synthesized performance is adopted, then the number of superior strategies is nine items, which is $33 \%$ of the original twenty-seven strategies. If the most important $20 \%$ of the strategies are selected, then six items strategies are be choosed. The strategies proposed by this research are somewhat inter-dependent. Some of those strategies above $50 \%$ of total synthesized performance are merged into six items. So, strategies $s_{6}$ and $s_{14}$ are merged with $s_{13}$, and $s_{12}$ is merged with $s_{19}$.

Second, the rationality of the results by GAEM ranking is discussed. The results in Table 3 show that if a strategy is linked to more goals, then its synthesized performance value is higher. Strategy $s_{13}$ for example is linked to three goals, so its total performance is the highest. Strategies $s_{1}, s_{6}, s_{7}, s_{9}, s_{12}, s_{14}, s_{18}, s_{21}, s_{22}$, and $s_{26}$ are linked to two goals. Of these, strategies $s_{1}, s_{6}, s_{9}$, $s_{12}, s_{13}, s_{14}, s_{18}, s_{21}$, and $s_{22}$ have higher performances and were selected as primary strategies. The synthesized performance of a strategy is the product the weight of the goal multiplied by the score of the strategy. Therefore, the more goals the strategy is linked to, the higher a synthesized performance it obtains. Furthermore, in case a certain strategy implement can benefit more goals, it becomes the preferred choice of the decision maker. 
Finally, the effect of the imperfect structure model and its application is discussed. The GAEM constructed in this study utilizes the two-stage Delphi questionnaire. In the first stage, the total 162 elements of GA matrix from six goals and twenty-seven strategies are filtered out, and 39 items are selected (Table 3), one-quarter of the original, in the empirical study. In doing so, a smaller quantity of questionnaire data is needed for the second stage, which reduces the chance of data errors. The GAEM model is useful when there are a large number of evaluation alternatives. Generally, the GAEM is pertinent for strategy formulation in the public sector and macro evaluation cases, especially for multi-objective cases.

\section{CONCLUSIONS}

Based on the results of the above analysis, the conclusions and policy recommendations can be summarized as follows:

This research employed an imperfect evaluation structure and a two-stage Delphi questionnaire to establish a GAEM. Thirty nine out of 162 elements of the GA relations were selected for the first stage in this case study, and then a performance survey was used for the second stage. This empirical study has proven that the number of survey data can be reduced by one quarter of the original data, which reduces the probablities of data errors.

The integrated relative weights of the goals for all of the resources of the port of Kaohsiung by questionnaire are as follows. Weight of $g_{5}$, enhancing the competitiveness of Kaohsiung, is $20.25 \%$ and is the highest goal. For $g_{1}$, re-engineering of the organizational system of the municipality and the port, the weight is $20.16 \%$. The weight of $g_{2}$, effective use of municipal and port land, is $17.66 \%$. Goal $g_{4}$, enhancing the transportation for both the municipality and the port, has a weight of $16.34 \%$. Goal $g_{6}$, creating a modern metropolis with sustainable development and a knowledge-based economy, has a weight of $15.24 \%$. The weight of $g_{3}$, to enhance the software and hardware of the old wharves, is $10.35 \%$.

From this empirical study, there are six superior strategies for resource integration by the port of Kaohsiung, as follows: 1. Promote the integration of the redevelopment of the old wharves through urban planning; 2. reinforce the existing ODA's function; 3 . speed up the improvement of the traffic link between the Process Export Zone and the container terminals; 4. integrate the current maritime network and make it a navigation-port-tariff information system; 5 . invest overseas; 6. use Kaohsiung's strength of airport and seaport to enhance its functions of sea-air reprocessing and transshipment services.

Due to the large number of strategies, these strategies can be classifies into several groups before applying the GAEM model. If the goals are too ambiguous, it would be difficult to judge achievement by interviewees, so redefining the goals is an appropriate way to respond.

\section{ACKNOWLEDGEMENTS}

The authors would like to thank National Science Council of the Republic of China for its support of the research NSC 89-2611-E-019-032. The content of this paper is part of the results from that study.

\section{REFERENCES}

1. Bovaird, T., "Strategy Evaluation in a Multi-stakEholder Environment," EURAM Conference, Stockholm, May 9-11 (2002).

2. Containerisation International Yearbook, National Magazine Co. Ltd., London (1993-2002).

3. David, F.R., Strategic Management, Concepts and Cases, Eighth Edition, Prentice Hall, New York (2001).

4. Dyson, R.G., Strategic Planning: Models and Analytical Techniques, John Wiley and Sons, Chichester (1990).

5. Dyson, R.G. and Foster, M.J., "Effectiveness in Strategic Planning," Eur. J. Operat. Res., Vol. 5, No. 3, pp. 163-170 (1980).

6. Foster, M.J. and Foster, D.N., "Assessing the Effectiveness of Strategic Planning," Omega, Vol. 10, No. 1, pp. 19-23 (1982).

7. Frankel, E.G., "Strategic Planning Applied to Shipping and Ports," Marit. Pol. Manag., Vol. 16, No. 2, pp. 123132 (1989).

8. Hill, M., "A Goals-Achievement Matrix for Evaluating Alternative Plans," J. Am. Inst. Town Planners, Vol. 34, No. 1, pp. 19-38 (1968).

9. Hill, M., Planning for Multiple Objectives: An Approach to the Evaluation of Transportation Plans, Monograph No. 5, Regional Science Research Institute, Philadelphia, Pennsylvania (1973).

10. Huang, M.-J., Huang, W.-C., Teng, J.-Y., and Wu, S.-C., "Ports Competitiveness Evaluation- Case Study of Eastern Asian Container Ports," Proceedings of Eastern Asia Society for Transportation Studies, Hanoi, Oct. 24-27 (2001).

11. Huang, M.-J., Huang, W.-C., Teng, J.-Y., and Wu, S.-C., "Competitiveness Evaluation for Eastern Asian Container Orts by Using Grey Relational Analysis Method," J. Grey Syst., Vol. 14, No. 3, pp. 139-50 (2002).

12. Huang, W.-C., Teng, J.-Y., Huang, M.-J., and Wu, S.-C., "Integration of the AHP and SWOT Analysis for Port 
Competition Evaluation in the Eastern Asian Region," Proceedings of the Fifth International Symposium on the Analytic Hierarchy Process, Kobe, Japan (1999).

13. Huang, W.-C., Teng, J.-Y., Huang, M-J., and Kou, M.-S., "Port Competitiveness Evaluation by Fuzzy Multicriteria Grade Classification Model," J. Mar. Sci. Technol., Vol. 11, No. 1, pp. 53-60 (2003).

14. Hwang, C.L. and Yoon, K., Multiple Attribute Decision Making: Methods and Applications, Springer-Verlag, New York (1981).

15. Lee, K-L., Huang, W-C., Kuo, M-S., and Lin, S-C., "Competitiveness Modal of International Distribution Park Using the Virtual Value Chain Analysis," J. Eastern Asia Soc. Transport. Stud., Vol. 4, No. 4, pp. 313-325 (2001).

16. National Taiwan Ocean University (NTOU), Laboratory for Port and Logistics Planning, Strategic Planning for Resource Integration of Kaohsiung Port Region, Final Report, Kaohsiung City Government, Kaohsiung (2002). (in Chinese)

17. Nijkamp, P. and Voogd, H., An Introduction to Multicriteria Evaluation: Multiple Criteria Decision Methods and Applications, Springer-Verlag, London (1985).

18. Verhoeff, J.M., "Seaport Competition: Some Fundamental and Political Aspects," Marit. Pol. Manag., Vol. 8, No. 1, pp. 49-60 (1981).

19. Voogd, H., Multicriteria Evaluation for Urban and Regional Planning, Pion, London (1983).

\section{APPENDIX. DEVELOPMENT STRATEGIC ALTERNATIVES FOR THE PORT AND CITY OF KAOHSIUNG}

$\mathrm{s}_{1}$. Incorporating the development project of the urban plan with the port by reinforcing the existing Ocean Development Administration's (ODA) function under the structure of city and port integration.

$\mathrm{s}_{2}$. Integrating the functions and duties of the environmental protection departments of the city and the port. Timely investigations, the elimination of the sources of the pollutants, and the re-purification of the water should be adopted and vigorously maintains so as to create a quality environment to attracting tourists and visitors.

$s_{3}$. An objective assessment procedure should be adopted for land-use planning of the port, so as to create maximal benefits. The assessment approach should consider compatibility and feasibility between urban land-use and port facilities.

$\mathrm{s}_{4}$. A full-scale incorporated development of a unified Kaohsiung City, Kaohsiung County and Pingtung County should be undertaken. Southbound development of the offshore area would be an applicable option for new port-land development. For future development, emphasis should be placed on reducing environmental and traffic impacts, controlling of the port-building schedule, and increasing land benefits.

$\mathrm{s}_{5}$. Thoroughly re-examine the state-run enterprises on state-owned land, both inside and outside of the port in order to reduce costs and increase the return on investment.

$s_{6}$. Redevelopment projects should incorporate the Chizin Peninsula, similar to the Santosa project in Singapore (Santosa Tourism Bureau, 2000), where the redevelopment includes natural ecology, historic sites, cultural, recreational and leisure facilities.

s $_{7}$. Two national programs need to be applied for, focusing on the revitalization of the passenger transport of the old wharves and the development of international logistics (for cargo). The development of this port is a comprehensive project, similar to Japan's MM21 and KP2020, and we must achieve multiplied effects and avoid budget waste.

$s_{8}$. Due to high population density, one of the adoptable solutions should be developing a mass rapid transport system for the urban area. The port area's outbound arterial railway should be connected to various sites with enhanced public access to attract more visitors to its waterfront.

$\mathrm{s}_{9}$. Speeding up and strengthen the traffic link between the Process Export Zone and the container terminals to enhance the function of reprocessing and offshore transshipment.

$s_{10}$. Streamlining the inter- and intra-terminal traffic flow to prevent conflicts between passenger and freight transport outside the port.

$s_{11}$. International logistics should be built up by incorporating logistics parks, logistics centers (public and private) and a logistics operator.

$s_{12}$. Reviewing the current supply and demand of the domestic fisheries and relocate the fishery operation to other exclusive fishery zones or to neighboring fishery ports.

$s_{13}$. In view of the close trading partnership with China and Japan, the promotion of redevelopment of the old wharves (for guest use) and international logistics (for cargo) should be redefined as economic investment projects on a national and international level.

$s_{14}$. The development projects including the Hamasen Renewal Project, Kuyeng Waterfront Project, Taisuger Commercial and Trade Park, Chizin Recreational Park and so on, should be systematically integrated. Integrate the redevelopment of the old wharves with the urban renewal projects, including the overall planning, general consultancy, facility 
planning, and all facets of development and operation considerations.

$s_{15}$. Evaluating the priorities of the projects using an objective decision-making process based on the limited budget support (capital investment of NT\$ 100-200 billion).

$s_{16}$. All legal systems including tariff-reserved zones, science-based industrial parks, reprocessing and export zones, offshore shipping centers and logistics centers should be incorporated into a single legal system of a Free Trade Zone.

$s_{17}$. In view of upcoming privatizations of state-run enterprises such as petroleum, steel and shipbuilding, none of the land or berths presently used by these state corporations should be released to any future private owner. Thus the fundamental meaning of justice resided within the Law of Port and Law of Land would be properly maintained.

$s_{18}$. Using Kaohsiung's strength of only a 20 -minute drive from airport to seaport and its location in Asia Pacific Area to enhance the features and advantages of reprocessing and transshipment services of a sea-air.

$s_{19}$. The geographical location in conjunction with Singapore and shanghais and its modernized port facilities should give Kaohsiung cutting edge competitiveness in its global logistics strategy. The services-based framework for its globalization should also take into consider the National Territory Development particular for the redevelopment of Southern Taiwan. Focusing on international logistics, and on the import and export services based in the geographically excellent location of Kaohsiung and modernize its facilities.

$s_{20}$. Emulate the Japanese model by constructing a combined pipeline, power and communications cable network, thus effectively integrating various resources, such as the old pipeline system and the wide-band network for the areas to be renewed. $s_{21}$. The city government should invest internationally, following the example of Kaohsiung Bank, and combine the Port Bureau, carriers, major business clients, etc., and include them in their investment portfolio, such as intelligent infrastructure, logistics, and terminal operator.

$s_{22}$. Initiate the necessary steps to integrate the current maritime network, such as MT-Net, Port-Net, and Trade-VAN to make them into a navigation-porttariff information system. The system should serve future needs by linking the City Government Network to be a combined city/port intelligent system.

$s_{23}$. Adopting advanced technology such as Global Positioning System (GPS), Intelligent Transportation System and Commercial Vehicle Operation (ITS$\mathrm{CVO}$ ) to enhance the transportation infrastructure and cargo control serving the needs for an improved access to and from the surrounding berths.

$s_{24}$. Strengthening partnerships with neighboring countries and cities through exchanges, such as sister cities, port coalitions, marketing and two-way investment.

$s_{25}$. The redevelopment of the old wharves and waterfront recreational sites should integrate all suitable transport systems, including Du Du Trains, MRT, recreational boat, bike lanes and the Blue Highway. The planning should be coordinated with other neighboring tourist sites, including Kaohsiung City/ County and Ping Tung County.

$s_{26}$. Port land should have multi-purpose use, with a proper segregation among various needs for tourism, hotel accommodations for visitors and international logistics. All resources need to be effectively integrated in the planning.

$s_{27}$. Setting up an efficient system for collecting boatproduced waste, with a treatment facility and an environment monitoring system to keep boat-related pollutants out of port waters, ensuring a clean waterfront. 